\title{
Beyond the antipredatory defence: Honey bee venom function as a component of social immunity
}

\author{
David Baracchi ${ }^{\mathrm{a}, *}$, Simona Francese ${ }^{\mathrm{b}}$, Stefano Turillazzi ${ }^{\mathrm{a}, \mathrm{c}}$ \\ a Università degli Studi di Firenze, Dipartimento di Biologia Evoluzionistica “Leo Pardi", Via Romana 17, 50125 Firenze, Italy \\ ${ }^{\mathrm{b}}$ Biomedical Research Centre, Sheffield Hallam University, Howard Street, Sheffield S1 1WB, UK \\ ${ }^{\mathrm{c}}$ Centro di Servizi di Spettrometria di Massa, dell'Università di Firenze, Viale G. Pieraccini, 50139 Firenze, Italy
}

\section{A R T I C L E I N F O}

\section{Article history:}

Received 6 April 2011

Received in revised form 29 August 2011

Accepted 30 August 2011

Available online 10 September 2011

\section{Keywords:}

A. mellifera

A. cerana

A. dorsata

A. andreniformis

Collective immunity

MALDI-TOF MS

\begin{abstract}
A B S T R A C T
The honey bee colonies, with the relevant number of immature brood and adults, and stable, high levels of humidity and temperatures of their nests, result in suitable environments for the development of microorganisms including pathogens. In response, honey bees evolved several adaptations to face the increased risks of epidemic diseases. As the antimicrobial venom peptides of Apis mellifera are present both on the cuticle of adult bees and on the nest wax it has been recently suggested that these substances act as a social antiseptic device. Since the use of venom by honey bees in the context of social immunity needs to be more deeply investigated, we extended the study of this potential role of the venom to different species of the genus Apis (A. mellifera, Apis dorsata, Apis cerana and Apis andreniformis) using MALDI-TOF mass spectrometry techniques. In particular we investigated whether (similarly to A. mellifera) the venom is spread over the body cuticle and on the comb wax of these three Asian species. Our results confirm the idea that the venom functions are well beyond the classical stereotype of defence against predators, and suggest that the different nesting biology of these species may be related to the use of the venom in a social immunity context. The presence of antimicrobial peptides on the comb wax of the cavity-dwelling species and on the cuticle of workers of all the studied species represents a good example of "collective immunity" and a component of the "social immunity " respectively.
\end{abstract}

(c) 2011 Elsevier Ltd. All rights reserved.

\section{Introduction}

The use of weapons as defence against enemies was one of the major factors that favoured the evolution of social life in insects (Andersson, 1984; Starr, 1985). In the eusocial Aculeate Hymenoptera, the stinging apparatus and the venom, originally evolved as devices to paralyse preys, became arms to defend the colony mainly from the attacks of vertebrate predators. More than any other group of social insects, honey bee colonies, with their rich store of honey and pollen, high mass of immature brood and adults, are rewarding targets for many predators. At the same time,

\footnotetext{
* Corresponding author. Tel.: +39 55 2288218; fax: +39 55222565 .

E-mail address: david.baracchi@gmail.com (D. Baracchi).
}

another important selective force, directly consequent to the development of a complex sociality, is represented by the necessity of defence against pathogens and parasites (Otvos, 2000). Indeed, the constant and relatively high temperature and the high humidity levels maintained in a bee nest results in a suitable environment for the incubation of microorganisms (protozoa, fungi, bacteria and viruses) which in most cases can be pathogenic. In response, honey bees have evolved several physiological, behavioural, and organisational adaptations to fight the increased risks of epidemic diseases (Wilson-Rich et al., 2009). The strategies honey bee species adopt to reduce these risks include the collection and use of antimicrobial natural substances (such as propolis (Simone-Finstrom and Spivak, 2010)) and glands secretions which are particularly 
important as primary barriers to infection (Zasloff, 2002; Stow et al., 2007). Venom gland, in honey bees as well as in other Hymenoptera, has recently been reported as an important source of antimicrobial substances (KuhnNentwig, 2003). The application of venom on the body surface as a way of protection against pathogens has been suggested for the ants Solenopsis invicta (Obin and Vander Meer, 1985) and Pachycondila goeldii (Orivel et al., 2001), for the paper wasp Polistes dominulus (Turillazzi et al., 2006) and for the honey bee Apis mellifera (Baracchi and Turillazzi, 2010). Honey bee venom is composed of a wide spectrum of molecules, ranging from biogenic amines to peptides and proteins, the structure and function of which have been determined in great part (Kreil, 1973; Hoffman, 1996). Three peptides are the major compounds of the venom fraction ranging from 1000 to 4000 Da. Melittin, a basic peptide of 26 residues ( $\sim 2.8 \mathrm{kDa}$ ), accounts for $50 \%$ of the venom dry weight (Ownby et al., 1997; de Lima and Brochetto-Braga, 2003) and exhibits an amphipathic structure and lipid membrane permeability. Apamin is a small 18 amino acids (MW $\sim 2.0 \mathrm{kDa}$ ) peptide accounting for less than $2 \%$ of venom dry weight which presents a neurotoxic action (de Lima and Brochetto-Braga, 2003). MCD peptide comprises 22 amino acid residues (MW $\sim 2.6 \mathrm{kDa}$ ) and causes mast cell break down; it accounts for about $2 \%$ of the venom dry weight (de Lima and BrochettoBraga, 2003). Recently we have confirmed that these three molecules at $m / z$ 2026.82, 2586.53 and 2845.63 together with many other venom compounds are present also on the cuticle of the workers and on the nest wax of $A$. mellifera (Baracchi and Turillazzi, 2010). As the antiseptic properties of melittin is well documented (Kuhn-Nentwig, 2003) and an antimicrobial action was also suggested for apamin and MCD (Froy and Gurevitz, 1998), we hypothesized that venom peptides act as a colonial antimicrobial protection (Baracchi and Turillazzi, 2010). The wax comb could represent a "medium" where the venom is deposited to act as a social antiseptic device. In this case, the use of the venom blend can be considered as a component of the so called social immunity (see Cremer et al., 2007; WilsonRich et al., 2009; Cotter and Kilner, 2011) together with other physiological, behavioural and organisational adaptations, such as social fever (Starks et al., 2000), nest construction with antimicrobial material (Simone et al., 2009) and hygienic behaviours against pathogens and parasites (Spivak and Gilliam, 1998a,b; Richard et al., 2008). The use of venom by $A$. mellifera in the context of social immunity, as well as the composition and the role of venom in other species of the genus Apis, needs to be more deeply investigated, for example with respect to the ecology and the environmental constraints. For these reasons in the present research we extended the study of the venom peptides across three other species of the genus Apis: Apis dorsata, Apis cerana and Apis andreniformis.

Within the nines species of Apis, there is a wide variation in the nesting biology; according to their nests features, species are divided into two groups: the cavitydwelling species (A. (Apis) cerana, A. (Apis) koschevnikovi, A. (Apis) mellifera, A. (Apis) nigrocincta and A. (Apis) nuluensis) and the open nesting species. The latter are further divided, on the basis of their body size in dwarf honey bees (A. (Micrapis) florea and A. (Micrapis) andreniformis) and giant honey bees (A. (Megapis) dorsata and A. (Megapis) laboriosa).

The aim of this study is to evaluate if the environmental constraints (as a consequence of the different nesting biology) and the ecology of the three subgenera of honey bees could affect the composition and the use of the venom in the logic of social immunity. We performed, for the first time, an analytical survey of the medium weight polar substances of the venom of $A$. cerana, A. dorsata and $A$. andreniformis using MALDI-TOF MS. Subsequently, we investigated whether and how, similarly to A. mellifera, venom peptides were spread both over the body cuticle and on the wax of the nest of these three Asian species.

\section{Materials and methods}

\subsection{Venom and cuticular compounds collection}

During January 2010, 20 newly emerged workers, 30 nurses, 20 guards, 30 foragers and 20 drones were collected and killed by freezing from a colony of $A$. cerana hosted in a wooden small hive at Bukit Katil, Melaka State, Malaysia. We also collected 3 queens from other colonies in the same locality and 40 foragers from a wild hive of $A$. cerana found at Genting Sempah, Pahang State, Malaysia. We then collected and killed by freezing 30 newly emerged workers and 30 adult workers from a wild colony of $A$. dorsata at Bukit Katil, Melaka State, Malaysia, and 30 adult workers from a wild colony of $A$. andreniformis found at Genting Tea Estate, Pahang State, Malaysia. Unfortunately, neither queen nor drones were found in these two latter colonies. Half specimens of each species were dissected and drops of their venom were extracted directly from the tip of the sting with a small capillary glass tube after gently squeezing the venom sac with a glass plate (capillary extraction). A small piece of the capillary containing venom was then placed in a $250 \mu \mathrm{l}$ glass conical insert with $50 \mu \mathrm{l}$ of methanol. The other half of the specimens of each species, the queen and the drones of $A$. cerana were singly washed in $200 \mu \mathrm{l}$ of methanol for $2 \mathrm{~min}$ to extract the overall epicuticular polar compounds. During this procedure each bee was held by the tip of its abdomen using a pair of forceps to prevent any possible methanol contamination by the venom. All the extracts were analysed by MALDI-TOF mass spectrometry.

To exclude any possible contamination of the cuticle with the venom during the dissection procedure, we also performed methanol in situ micro-extractions on the first gastral tergite of 4 intact workers of $A$. cerana and of 4 intact workers of $A$. dorsata. We directly dispensed $5 \mu \mathrm{l}$ of methanol on the cuticle pipetting it back at once and then mixing $1 \mu \mathrm{l}$ of the extract with $1 \mu \mathrm{l}$ of $\alpha$-cyano-4hydroxycinnamic acid ( $\alpha$-CHCA) $(10 \mathrm{mg} / \mathrm{ml})$ dissolved in 70/30 Acetonitrile/TFA $0.1 \%$ (MALDI matrix) previously deposited on a MALDI plate (Turillazzi et al., 2006). The venom and the cuticle of 30 foragers belonging to three colonies of $A$. mellifera ligustica (Florence, Central Italy) was also extracted and analysed with the same method in order to obtain spectra comparable with those of the Asian species. Finally we collected samples of wax from the 
combs of the four species and extracted them in $200 \mu$ of methanol for $2 \mathrm{~min}$ before analysing the extracts by MALDI-TOF mass spectrometry.

\subsection{Mass spectrometry analyses}

\subsubsection{MALDI-TOF spectra profiling}

Methanol extracts of the venom and of the overall cuticle from each individual bee were analysed using a MALDI-TOF/TOF Ultraflex III (Bruker Daltonics, Bremen, Germany). The instrument was operated in positive ion reflector mode. The accelerating voltage and the Ion Source 2 were set to 25.0 and $21.9 \mathrm{kV}$, respectively, and the delay time was $20 \mathrm{~ns}$. One $\mu \mathrm{l}$ of the sample was mixed with MALDI matrix (1:1, vol:vol), previously spotted on a stainless steel MALDI target; 800 shots were automatically accumulated for each sample. External calibration was performed with the Bruker Standard Peptide Calibration kit $(\mathrm{m} / z$ 1000-3500) and the peptidic fraction of the samples was acquired in the range $m / z$ 800-4000.

\subsubsection{Peptide identification (MALDI-TOF/TOF MS and LC-ESI high resolution MS (LC-ESI/HRMS))}

MS/MS spectra of some cuticular peptide ions were recorded on a MALDI-TOF/TOF Ultraflex III mass spectrometer (Bruker Daltonic, Italy) using the LIFT ${ }^{\mathrm{TM}}$ method. The sequence of the peptides was deduced by interpreting the MS/MS spectra and by comparing the obtained sequences with those reported in the literature (data not shown). The cuticular extraction samples were submitted also to LC-nano ESI-HRMS analysis by using an Ultimate 3000 HPLC system (Dionex LC Packings, Sunnyvale, CA) coupled to an LTQ Orbitrap mass spectrometer (Thermo Electron Corporation, San Jose, CA). A PepSwift Monolithic PS-DVB column $(200 \mu \mathrm{m}$ I.D. $\times 5 \mathrm{~cm}$, Dionex LC Packings $)$ was used and it was maintained at a temperature of $45^{\circ} \mathrm{C}$. The gradient solvent system for the micro pump, consisting of $0.1 \%$ aqueous formic acid $(A)$ and acetonitrile with $0.1 \%$ of formic acid (B), was the following: $0-2 \mathrm{~min}, 2 \% \mathrm{~B} ; 2-12 \mathrm{~min}$, $2-50 \%$ B; $12-12.5$ min, $50-90 \%$ B; $12.5-15$ min, $90 \%$ B; $15-$ $15.5 \mathrm{~min}, 90-2 \% \mathrm{~B} ; 15.5-22.5 \mathrm{~min}, 2 \% \mathrm{~B}$. The flow rate was maintained at $3 \mu \mathrm{L} / \mathrm{min}$ throughout the analysis. In all cases the injection volume was $10 \mu \mathrm{L}$. The nanoESI interface and mass spectrometer parameters were the following: spray voltage $1.25 \mathrm{kV}$, capillary voltage $40 \mathrm{~V}$, capillary temperature $210{ }^{\circ} \mathrm{C}$, tube lens $115 \mathrm{~V}$. Data were acquired in a range $\mathrm{m} / \mathrm{z} 400-2000$ with a nominal resolution of 30,000 (at $\mathrm{m} / \mathrm{z}$ 400 ) in positive ion-mode. Data were processed by using the Xcalibur software with the "Xtract" tool for the calculation of deconvoluted average and monoisotopic molecular weight.

\subsection{Statistical analyses}

Calibrated spectra were imported into the ClinProTools $^{\mathrm{TM}}$ (CPT) software and processed with a procedure described in a previous study on A. mellifera (Baracchi and Turillazzi, 2010). The software calculated the areas of the most important peaks that account for statistical differences between the venom of the various groups. These peaks were used by the software to generate a model to classify the spectra and eventually to assign any other new spectrum to a particular group. CPT parameters used for model generation in the various analyses were standardized in order to obtain comparable results: Peak width: 0.01; Smoothing (width: 5 Da, cycles: 1); Average Peak List Calculation (Relative Threshold Base Peak: 0.01, Signal-to-Noise Threshold: 3, Limit Peak Number: false); Area Calculation (Integration Type: end point level); Peak Selection (Use All Peaks: true, Sort Mode: P-value tta); Model Generation (Algorithm: Quick Classifier); Cross Validation (Percent Leave Out: $20 \%$, Number of Iterations: 10).

\section{Results}

\subsection{Venom reference spectra}

3.1.1. Venom of A. andreniformis, A. cerana, A. dorsata and A. mellifera

The identification of melittin for A. cerana, A. dorsata, A. andreniformis and apamin for $A$. andreniformis was confirmed by sequencing the respective peaks by MALDITOF MS/MS analysis and via determination of the exact MW with LTQ Orbitrap analysis (A. cerana: Exp. $\mathrm{Mw}=2845,75 \mathrm{Da}$; A. dorsata: Exp. $\mathrm{Mw}=2846,72$ Da and Apis andreniformins: melittin Exp. Mw $=2817,72 \mathrm{Da}$ and apamin Exp. Mw, 2073,18 Da). The identification of apamin for $A$. cerana and $A$. dorsata was confirmed by the determination of the exact MW using the LTQ Orbitrap (A. cerana: Exp. $\mathrm{Mw}=2026,89 \mathrm{Da}$ and A. dorsata: Exp. $\mathrm{Mw}=2026.83 \mathrm{Da})$.

The CPT software found $26,27,27$ and 29 main peaks in the venom of $A$. cerana, $A$. dorsata, $A$. andreniformis and A. mellifera respectively. These compounds have molecular weights in the range 990-3020 Da, 998-3049 Da, 9903143 Da and 1006-3148 Da respectively (Table 1).

Using the venom spectra of these four species, CPT model recognized $98.33 \%$ of workers to their species with a cross validation of $95.7 \%$. In the cross validation test the $100 \%$ of both $A$. mellifera and $A$. andreniformis, the $90 \%$ and 93\% of $A$. dorsata and $A$. cerana respectively were correctly assigned to their group.

\subsubsection{Venom of different classes of workers of A. cerana}

Fig. 1A reports the representations in Gel View (Facility supplied by the CPT software) of the pure venom of the four classes of workers analysed in $A$. cerana: newly emerged workers $(N=10)$, nurses $(N=15)$, guards $(N=10)$ and foragers $(N=15)$. CPT model recognized correctly only $67.51 \%$ of the bees in the assigned class with a cross validation of $65.1 \%$ using melittin as the main peak for discrimination (Table 2). However the newly emerged bees were recognized at $100 \%$ with respect to all adult bees. In fact, as it can be observed from the Gel View figure, the venom of the newly emerged bees visibly differentiates for the lack of all the most abundant peaks, like apamin and melittin, with respect to those of the other groups. When we compared the venom of the foragers belonging to the two different sampled colonies the CPT model recognized correctly $76.1 \%$ of the bees with a cross validation of $65.7 \%$. 
Table 1

List of the peaks ranging from 950 Da to 4000 Da identified by CPT in a set of $40,30,30$ and 30 workers crude venom of $A$. cerana, A. dorsata, $A$. andreniformis and $A$. mellifera respectively and relative percentages in brackets. As $Z=1$, value are in equivalent Daltons.

\begin{tabular}{|c|c|c|c|}
\hline \multicolumn{4}{|c|}{ Venom Peaks $(\mathrm{m} / \mathrm{z})$} \\
\hline Apis cerana & Apis dorsata & Apis andreniformis & Apis mellifera \\
\hline $990(0.001)$ & $998(0.001)$ & $990(0.013)$ & $1006(0.001)$ \\
\hline $1017(0.001)$ & $1073(0.001)$ & $1017(0.011)$ & $1014(0.44)$ \\
\hline $1028(0.001)$ & $1260(0.001)$ & $1039(0.115)$ & $1024(0.001)$ \\
\hline $1045(0.001)$ & $1274(0.001)$ & $1042(0.005)$ & $1034(0.002)$ \\
\hline $1260(0.001)$ & $1897(0.00)$ & 1307 (0.009) & $1060(0.001)$ \\
\hline $1430(0.001)$ & $1973(0.001)$ & $1355(0.003)$ & $1066(0.001)$ \\
\hline $1442(0.011)$ & $1991(0.11)$ & $1420(0.072)$ & $1105(0.003)$ \\
\hline $1997(0.001)$ & $1999(0.001)$ & $1429(0.212)$ & $1294(0.11)$ \\
\hline $2013(0.029)$ & $2014(0.58)$ & $1938(0.116)$ & $1434(0.14)$ \\
\hline apamin (1.85) & apamin (4.31) & $2035(0.240)$ & $1443(0.27)$ \\
\hline $2113(0.001)$ & $2083(0.001)$ & $2059(0.518)$ & $1454(0.062)$ \\
\hline $2190(0.005)$ & $2121(0.001)$ & apamin (6.10) & $1462(0.034)$ \\
\hline $2208(0.046)$ & $2175(0.001)$ & $2083(0.113)$ & $1510(0.001)$ \\
\hline $2269(0.001)$ & $2190(0.001)$ & $2511(0.152)$ & $1524(0.047)$ \\
\hline $2307(0.001)$ & $2239(0.001)$ & $2780(0.760)$ & $1668(0.039)$ \\
\hline $2592(0.17)$ & $2575(0.001)$ & melittin (80.54) & $1761(0.001)$ \\
\hline 2793 (0.79) & $2793(0.72)$ & $2830(0.575)$ & $1797(0.011)$ \\
\hline $2809(4.05)$ & $2811(5.39)$ & $2875(1.917)$ & $1996(0.17)$ \\
\hline $2820(0.53)$ & $2820(1.00)$ & $2899(0.580)$ & $2013(1.03)$ \\
\hline melittin (88.47) & melittin (82.87) & $2918(1.366)$ & apamin (16.16) \\
\hline $2859(1.44)$ & 2859 (1.49) & $2940(0.473)$ & $2208(0.32)$ \\
\hline $2877(0.08)$ & 2906 (1.09) & $2981(5.065)$ & $2335(0.004)$ \\
\hline $2904(0.47)$ & $2946(0.16)$ & $2992(0.122)$ & $2435(0.12)$ \\
\hline $2993(0.28)$ & $2995(0.33)$ & $3002(0.167)$ & 2588 (1.17) \\
\hline 3009 (1.77) & $3010(0.44)$ & $3019(0.450)$ & $2793(0.44)$ \\
\hline \multirow[t]{4}{*}{$3020(0.037)$} & $3031(0.73)$ & 3037 (0.099) & $2809(2.81)$ \\
\hline & $3049(0.75)$ & $3143(0.197)$ & melittin (76.51) \\
\hline & & & $2879(0.001)$ \\
\hline & & & $3048(0.49)$ \\
\hline
\end{tabular}

\subsubsection{Venom of different classes of workers of A. dorsata}

Fig. 2A reports the representations in Gel View of the pure venom of the two classes of workers analysed in $A$. dorsata: newly emerged bees $(N=15)$ and older bees $(N=15)$. CPT model recognized correctly $100 \%$ of the bees in the assigned class with a cross validation of $96.3 \%$ using as main peaks for discrimination melittin, and those at $\mathrm{m} / \mathrm{z}$ 2809 and 2793 (Table 2). In this case, the newly emerged bees were characterized by the lack of all the main peaks with $\mathrm{m} / \mathrm{z}$ higher than 2500 which were present, instead, in the venom of the adult bees.

\subsection{Cuticular extracts reference spectra}

\subsubsection{Cuticular extracts of queens, drones and different age} classes of workers of A. cerana

The relative amount of substances detected by the MALDI MS in the total body methanol extracts of drones was very low with respect to those of the females. Precisely only 3 out of 20 analysed males presented melittin and apamin but only in traces. The main peaks found in the venom (melittin and apamin) were still the most abundant ones in the spectra of the cuticle extracts of the workers while other peaks, ranging from 1000 to 1100 Da, were exclusively present in the cuticle extracts. CPT model recognized $100 \%$ of queens and workers with a cross validation of $100 \%$ using the peaks at $m / z$ 1997, $\mathrm{m} / \mathrm{z} 2190$ and $m / z$ 1196. A CPT model applied to the workers in order to check for differences among newly emerged bees, nurses, guards and foragers did not furnish a good discrimination (56.88\% of recognition with $46.51 \%$ of cross validation) when using mellitin and peaks at $\mathrm{m} / \mathrm{z} 2307$ and 2435. However, also in this case, a perfect discrimination was obtained between newly emerged workers, which did not present any peaks in the cuticle extracts, and all the other females (Fig. 1B). When we compared the cuticular extract of the foragers belonging to the two different colonies analysed the CPT model recognized correctly $79.2 \%$ of the bees with a cross validation of $68.3 \%$.

\subsubsection{Cuticular extracts of workers of A. dorsata}

CPT model applied to newly emerged bees and adult bees provided a perfect discrimination (100\% of recognition with $100 \%$ of cross validation) using apamin and the peak at $m / z 2190$ (Table 2).

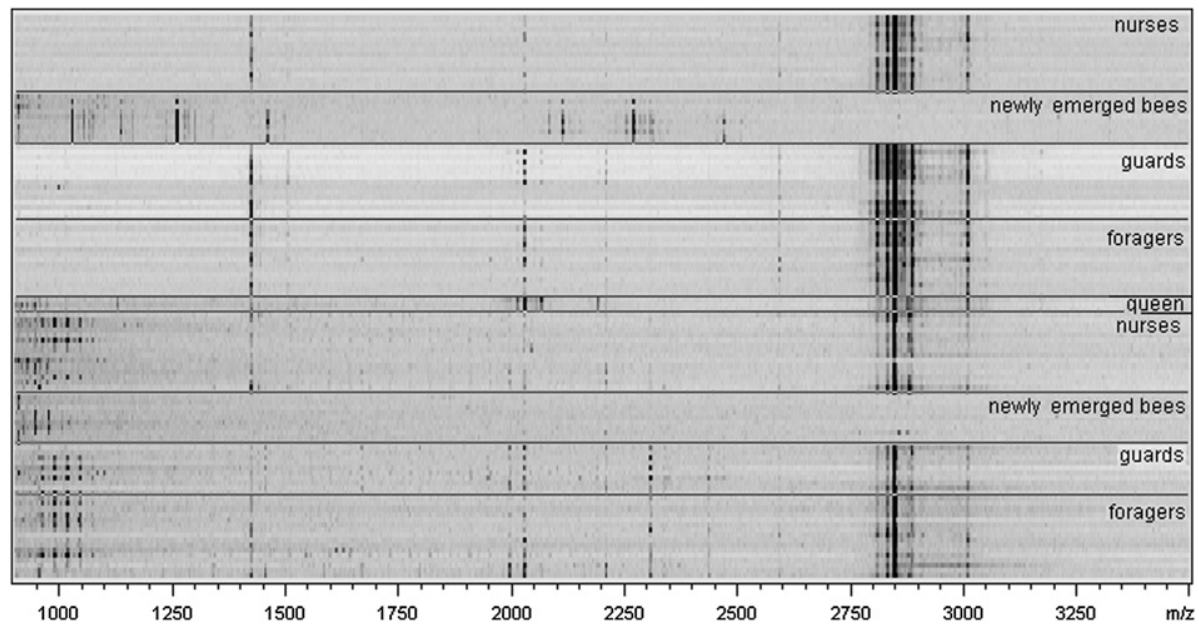

Fig. 1. Gel View Facility supplied by the CPT software in order to choose the most suitable peaks for discrimination of $A$. cerana venom (A) and cuticle (B). The spectral pattern of each individual is shown as a horizontal line with grey intensity standing for the relative abundance of the peaks. 
Table 2

CPT model for recognition of 950-4000 Da fraction of the venom of individuals belonging to different groups of bees and the cuticle of $A$. cerana and A. dorsata.

\begin{tabular}{|c|c|c|c|}
\hline & Recognition capability (\%) & Cross validation (\%) & Principal peaks $m / z$ \\
\hline \multicolumn{4}{|l|}{ Apis cerana } \\
\hline $\begin{array}{l}\text { Venom Foragers/guards/nurses/newly } \\
\text { emerged bees }(N=50)\end{array}$ & 67.51 & 65.10 & melittin \\
\hline Venom Adult bees/newly emerged bees $(N=50)$ & 100 & 100 & 2820 melittin \\
\hline Cuticular layer Queens/workers $(N=43)$ & 100 & 100 & 199721901196 \\
\hline $\begin{array}{l}\text { Cuticular layer Foragers/guards/nurses/newly } \\
\text { emerged bees }(N=50)\end{array}$ & 56.88 & 46.51 & 19972307 melittin \\
\hline $\begin{array}{l}\text { Cuticular layer Adult bees/newly emerged } \\
\text { bees }(N=50)\end{array}$ & 100 & 100 & 27932809 melittin 2904 \\
\hline \multicolumn{4}{|l|}{ Apis dorsata } \\
\hline $\begin{array}{l}\text { Venom Adult bees/newly emerged } \\
\text { bees }(N=30)\end{array}$ & 100 & 96.3 & 27932809 melitin \\
\hline $\begin{array}{l}\text { Cuticular layer Adult bees/newly emerged } \\
\text { bees }(N=30)\end{array}$ & 100 & 100 & apamin 2190 \\
\hline
\end{tabular}

\subsection{Comparison among extracts of the cuticle and of the} venom

The spectra registered from the cuticle extracts and the venom of workers of each species were imported together into the CPT software which selected 19, 19, 23 and 21 peaks in A. cerana, A. dorsata, A. andreniformis and A. mellifera respectively. Considering the threshold parameter of at least $0.1 \%$ for the quantity of a given peak, in $A$. cerana and $A$. mellifera 16 out of 19 and 16 out of 21 identified peaks were common to the venom and to the cuticle while in $A$. dorsata only 6 out of 19 peaks identified have been found in the venom and on the cuticle. Twelve out of the 23 identified peaks were common to the venom and to the cuticle in A. andreniformis. Three peaks in A. cerana, 4 in $A$. dorsata and $A$. andreniformis and 5 in $A$. mellifera workers have been detected only in the cuticle extracts even if these peaks were on average less than $3.0 \%$ of the quantities of the entire venom spectrum in all these species. Thirteen peaks in A. dorsata and 8 peaks in A. andreniformis were present only in the venom spectra and could not be found on the cuticle, while in $A$. cerana and $A$. mellifera all the peaks found in the venom were also found in the cuticle extracts (Figs. 3 and 4). In all the species, melittin was in percentage the most intense peak in the venom whereas in the cuticle extract melittin was almost absent in both A. dorsata and $A$. andreniformis which, instead, presented a higher peak intensity for apamin.

The spectra obtained with the in situ micro-extractions performed on the first gastral tergite of intact workers of $A$. cerana and $A$. dorsata, even if very feeble, substantially showed the presence of apamin and melittin on the cuticle of the first species and of apamin on the cuticle of the second one, confirming the results obtained on the body extracts.

\subsection{Comb wax extracts}

A further analysis performed on sample of comb wax of the nests of the four species demonstrated that the presence of venom compounds was an important feature of the hive environment at least in A. mellifera and A. cerana. Melittin was in percentage the most intense peak in the wax extracts of both these two cavity-dwelling species,

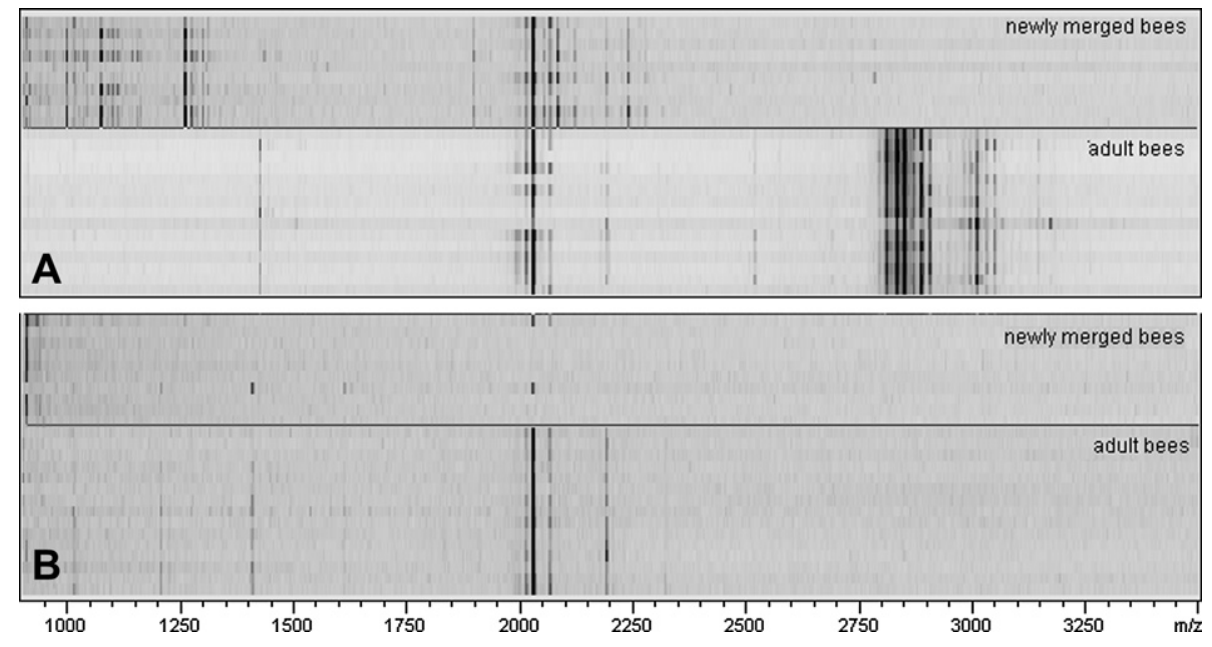

Fig. 2. Gel View Facility supplied by the CPT software in order to choose the most suitable peaks for discrimination of $A$. dorsata venom (A) and cuticle (B). The spectral pattern of each individual is shown as a horizontal line with grey intensity standing for the relative abundance of the peaks. 


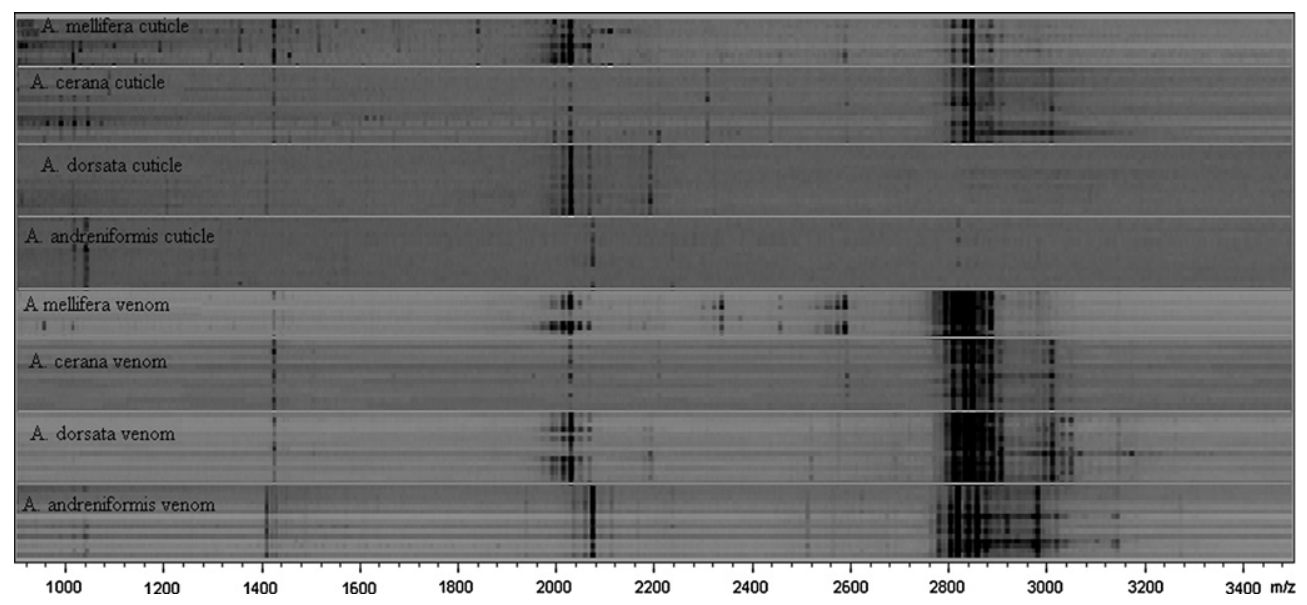

Fig. 3. Gel View Facility supplied by the CPT software when the data for the pure venom extract and for the cuticular extract of the four species were processed together.

while apamin was the second most intense peak only in A. mellifera and was present in minor quantities in A. cerana (reflecting the venom profile). On the contrary, no melittin nor apamin were found in the wax extracts belonging to the comb of the giant honey bee $A$. dorsata (where melittin was detected only in very low quantity) and of the dwarf honey bee $A$. andreniformis.

\section{Discussion and conclusion}

The venom of honey bees, as well as these of the other Hymenoptera species, is a complex and multifunctional secretion (Turillazzi, 2006). The present work shows as the medium molecular weight (MW) component of the venom (roughly from $900 \mathrm{Da}$ to $4000 \mathrm{Da}$ ) is quite constant through the genus Apis. Indeed, in all the studied species the main

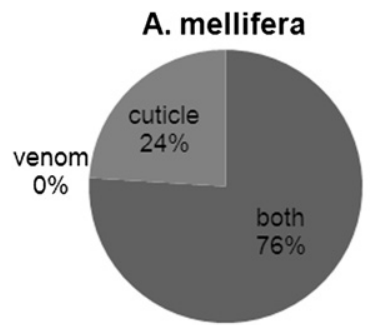

A. dorsata

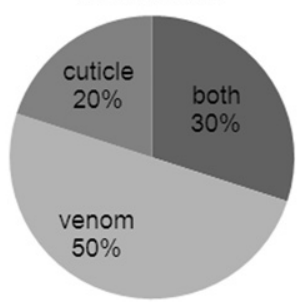

A. cerana

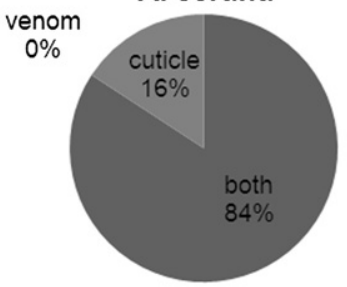

A. andreniformis

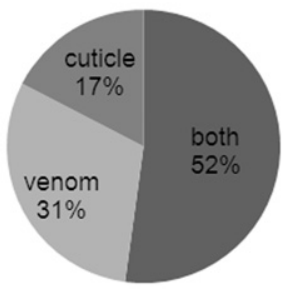

Fig. 4. Percentage of peaks characteristic of the cuticle, of the venom and present in both cuticle and venom. peaks are invariably melittin and apamin which represent on average the $77-88 \%$ and $2-16 \%$ of the medium MW venom component respectively. On the other hand, as recently described for $A$. mellifera (Baracchi and Turillazzi, 2010), we confirmed the presence of several minor peaks in all the analysed venoms. Even if at the present we do not know exactly the nature of these compounds, they have a sufficient degree of variance among the species representing also a useful tool for taxonomic studies as previously found for other Hymenoptera (Turillazzi et al., 2007; Baracchi et al., 2009).

Even if venom production is also influenced by the seasons (Ferreira et al., 2010), in an interesting paper, Schmidt states that $A$. cerana produces a quantity of venom which is half the quantity of that produced by $A$. dorsata and $A$. mellifera with the same body weight (Schmidt, 1995). However, comparing the 950-4000 Da fraction of the venom of $A$. cerana, $A$. dorsata and $A$. mellifera it is interesting to observe that the first one has the highest percentage of melittin with respect to the two other species. In this respect $A$. andreniformis, the smallest species of all examined in this research has even the highest of all. As melittin is the most toxic of all the compounds of the honey bee venom (Schmidt, 1995), the relative increase of this peptide could represent a compensation for the reduced size of the body and of the venom reservoir, supporting the defence against predators as one of the major driving force acting on venom.

However, as already stressed in the introduction, in the evolution of sociality the defencive function of the venom is coupled with its antimicrobial properties (Froy and Gurevitz, 1998; Kuhn-Nentwig, 2003). In this study we have found that the crude venom spectra belonging to the four species of honey bees show smaller differences with respect to those found in the cuticular extracts.

In particular, $A$. mellifera and A. cerana, have the cuticles profiles that are more similar (both for the number and for the relative abundance of the peaks) to the corresponding venom ones with respect to the two other species. 
Intriguingly, the major difference occurs between the cavity-dwelling species and the open nesting ones: notwithstanding melittin and apamin are present in the venom of every species they have been found only on the cuticle of $A$. cerana and $A$. mellifera while are almost absent on the cuticle of $A$. dorsata and $A$. andreniformis. Similarly, melittin and apamin are present in the wax of both the two cavity-dwelling species but are not evident in the wax of the combs of the giant honey bee $A$. dorsata and of the dwarf honey bee $A$. andreniformis. This seems to be related to the different ecology and nesting biology of these groups of species, that is, the composition of the venom could be adapted to different micro environmental conditions of the colony in the logic of social immunity. Even if the temperature and probably the humidity of the hive are well regulated in all the Apis species, it is likely that inside a cavity the environment is more suitable for the incubation of microorganisms with respect to open space and the cavity nesting species are exposed to higher levels of microbial challenge. Even if we could not make comparative measures such as moisture levels and debris accumulation increvices or open colonies, and the possible variables determining microbial communities are numerous (Atlas, 1984), it is evident that dryness limits both general and pathogenic fungal abundance and richness (Talley et al., 2002).

The presence of venom peptides on the cuticle of all the examined species (even if in a very different amounts) may be explained by the smearing of the venom on the cuticle during self-grooming movements. This agrees with the complete lack of any venom peptides on the cuticle of newly emerged bees. The fact that these peptides are of venom origin is confirmed by the complete absence of them on the cuticle of $A$. mellifera (Baracchi and Turillazzi, 2010) and $A$. cerana drones.

Thus, assuming that venom gland is the only source of some of the cuticular peptides, and that bees are not able to choose which peptides spread selectively on the cuticles, it is possible that differences in cuticular profiles depends on the time these compounds are able to remain on and how often venom is applied on the insect bodies. Thus, by comparing the relative overall amount of peptides both in the venom and in the cuticle extracts of the examined species (see Figs. 3 and 4 ), it seems that $A$. cerana performs the highest "venom bathing" activity followed by $A$. mellifera. This scenario is supported by the higher rate of grooming activity characteristic of $A$. cerana with respect to $A$. mellifera (Büchler et al., 1992). The considerable amount of cuticular antimicrobial peptides found in A. cerana agrees also with the fact that this species shows a higher production of haemolimph antimicrobial peptides, as a consequence of a higher exposure to pathogens and infections (Xu et al., 2009). Our results, in line with those of a previous paper (Baracchi and Turillazzi, 2010), suggest that the venom function is beyond the classical stereotype of defence against predators, and that the wax comb, at least in the cavitydwelling species, represents a "medium" where the venom is deposited to act as a social antiseptic device, representing a good example of "collective immunity" (sensu Cotter and Kilner, 2011). Further, in line with the recent broad definition by Cotter and Kilner, we propose to consider the presence of the major antimicrobial venom peptides (mainly melittin and, maybe, apamin) on the cuticle of the workers as a component of the so called "social immunity". This new definition encompasses the "herd immunity" (Frank, 1998) that arises from investment in personal immunity (i.e antimicrobial peptides spread on insect body), through the consequent reduction in the force of infection felt by neighbouring susceptible individuals (new emerged honey bees, drones and immature brood).

\section{Conflict of interest}

The authors declare that there are no conflicts of interest.

\section{Acknowledgements}

The authors thank Dr Elena Michelucci for her help in chemical analyses and Dr Giuseppe Mazza and Dr Alessandro Cini for their help on the field. We also thank Prof. Rosly Bin Hashim and Dr. Nurul Atika of the Institute of Biological Sciences of the University of Malaya and $\mathrm{Mr}$ Simon Hok for their support in Malaysia. Research was cofunded by the project APENET (DM 19735/7303/08 del 29/ 12/2008), and PRIN 2008 (prot. 2008KZ82RE).

\section{References}

Andersson, M., 1984. The evolution of eusociality. Annu. Rev. Ecol. Syst. 15, 165-190.

Atlas, R.M., 1984. Diversity of microbial communities. Adv. Microbiol. Ecol. 7, 1-47.

Baracchi, D., Dapporto, L., Teseo, S., Hashim, R., Turillazzi, S., 2009. Medium molecular weight polar substances of the cuticle as tools in the study of the taxonomy, systematics and chemical ecology of tropical hover wasps (Hymenoptera: Stenogastrinae). J. Zool. Syst. Evol. Res. 48, 109-114.

Baracchi, D., Turillazzi, S., 2010. Differences in venom and cuticular peptides in individuals of Apis mellifera (Hymenoptera: Apidae) determined by MALDI-TOF MS. J. Insect Phys. 56, 366-375.

Büchler, R., Drescher, W., Tornier, I., 1992. Grooming behaviour of Apis cerana, Apis mellifera and Apis dorsata and its effect on the parasitic mites Varroa jacobsoni and Tropilaelaps clareae. Exp. Appl. Acarol 16, 313-319.

Cotter, S.C., Kilner, R.M., 2011. Personal immunity versus social immunity. Behav. Ecol. 20, 1274-1281.

Cremer, S., Armitage, S.A.O., Schmid-Hempel, P., 2007. Social immunity. Curr. Biol. 17, 693-702.

de Lima, P.R., Brochetto-Braga, M.R., 2003. Hymenoptera venom review focusing on Apis mellifera.J. Venom. Anim. Toxins Incl. Trop. Dis. 9, 149-162.

Ferreira Jr., R.S., Sciani, J.M., Marques-Porto, R., Junior, A.L., Orsi Rde, O., Barraviera, B., Pimenta, D.C., 2010. Africanized honey bee (Apis mellifera) venom profiling: seasonal variation of melittin and phospholipase $\mathrm{A}(2)$ levels. Toxicon 56, 355-362.

Frank, S.A., 1998. Inducible defence and the social evolution of herd immunity. Proc. R. Soc. Lond., B., Biol. Sci. 265, 1911-1913.

Froy, O., Gurevitz, M., 1998. Membrane potential modulators: a thread of scarlet from plants to humans. FASEB J. 12, 1793-1796.

Hoffman, D.R., 1996. Hymenoptera venom proteins. Nat. Toxins 2, 169-186.

Kreil, G., 1973. Structure of melittin isolated from two species of honey bees. FEBS Lett. 33, 241-244.

Kuhn-Nentwig, L., 2003. Antimicrobial and cytolytic peptides of venomous arthropods. Cell Mol. Life Sci. 60, 2651-2668.

Obin, M.S., Vander Meer, R.K., 1985. Gaster flagging by fire ants (Solenopsis spp.): functional significance of venom dispersal behavior. J. Chem. Ecol. 11, 1757-1768.

Orivel, J., Redeker, V., Le Caer, J.P., Krier, F., Revol-Junelles, A.M., Longeon, A., 2001. Ponericins, new antibacterial and insecticida peptides from the venom of the ant Pachycondyla goeldii. J. Biol. Chem. 276, 17823-17829.

Otvos, J.D., 2000. Antibacterial peptides from insects. J. Pept. Sci. 6, 497-511. 
Ownby, C.L., Powell, J.R., Jiang, M.S., Fletcher, J.E., 1997. Melittin and Phospholipase A, from bee (Apis mellifera) venom cause necrosis of murine skeletal muscle in vivo. Toxicon $35,67-80$.

Richard, F.J., Aubert, A., Grozinger, C.M., 2008. Modulation of social interactions by immune stimulation in honey bee, Apis mellifera, workers. BMC Biol. 6, 50.

Schmidt, J.O., 1995. Toxicology of venoms from the honey bee genus Apis. Toxicon 33, 917-927.

Simone, M., Evans, J.D., Spivak, M., 2009. Resin collection and social immunity in honey bees. Evolution 63, 3016-3022.

Simone-Finstrom, M., Spivak, M., 2010. Propolis and bee health: the natural history and significance of resin use by honey bee. Apidologie $41,295-311$.

Spivak, M., Gilliam, M., 1998a. Hygienic behaviour of honey bees and its application for control of brood diseases and Varroa mites. Part I: hygienic behaviour and resistance to American foulbrood. Bee World $79,124-134$.

Spivak, M., Gilliam, M., 1998b. Hygienic behaviour of honey bees and its application for control of brood diseases and Varroa mites. Part II: studies on hygienic behaviour since the Rothenbuhler era. Bee World 79, 165-182.

Starks, P.T., Blackie, C., Seeley, T., 2000. Fever in honey bee colonies. Naturwissenschaften 87, 229-231.

Starr, C.K., 1985. Enabling mechanisms in the origin of sociality in the Hymenoptera: the sting's the thing. Ann. Entomol. Soc. Am. 78, 836-840.
Stow, A., Briscoe, D., Gillings, M., Holley, M., Smith, S., Leys, R., Silberbauer, T., Turnbull, C., Beattie, A., 2007. Antimicrobial defences increase with sociality in bees. Biol. Lett. 3, 422-424.

Talley, S.M., Coley, P.D., Kursar, T.A., 2002. The effects of weather on fungal abundance and richness among 25 communities in the Intermountain West. BMC Ecol. 2, 7.

Turillazzi, S., 2006. Polistes venom: a multifunctional secretion. Ann. Zool. Fennici 43, 488-499.

Turillazzi, S., Mastrobuoni, G., Dani, F.R., Moneti, G., Pieraccinila, G., la Marca, G., Bartolucci, G., Perito, B., Lambardi, D., Cavallini, V., Dapporto, L., 2006. Dominulin A and B: two New antibacterial peptides identified on the cuticle and in the venom of the social paper wasp Polistes dominulus using MALDI-TOF, MALDI-TOF/TOF, and ESI-Ion Trap. J. Am. Soc. Mass Spectrom. 17, 376-383.

Turillazzi, S., Bruschini, C., Lambardi, D., Francese, S., Spadolini, I., Mastrobuoni, G., 2007. Comparison of the medium molecular weight venom fractions from five species of common social wasps by MALDITOF spectra profiling. J. Mass Spectrom. 199, 205-242.

Wilson-Rich, N., Spivak, M., Fefferman, N.H., Starks, P.T., 2009. Genetic, individual, and group facilitation of disease resistance in insect societies. Annu. Rev. Entomol. 54, 405-423.

Xu, P., Shi, M., Chen, X., 2009. Antimicrobial peptide evolution in the Asiatic honey bee Apis cerana. PLoS ONE 4, e4239.

Zasloff, M., 2002. Antimicrobial peptides of multicellular organisms. Nature 415, 389-395. 